\title{
Evaluation of Mathematics Textbooks in Use in Ebonyi State Junior Secondary Schools, Nigeria
}

\author{
Ugama, J.O. Nnachi, N.O. Anugwo, M.N. Okpara, D. \\ Department of Science Education, Faculty of Education, Ebonyi State University, Abakaliki, Nigeria
}

\begin{abstract}
The study evaluated the content coverage, chapter summaries and readability index of twelve (12) approved and in use mathematics textbooks in Ebonyi State Junior Secondary Schools, Nigeria. Three research questions and 1 hypothesis guided the study. Evaluation design was used and simple random sampling technique was used to draw twelve out of fifty one textbooks in use. Twenty one junior secondary schools were drawn out of the two hundred and twenty one junior secondary schools in the State using non-proportional random sample to select seven schools from each of the three education zone. The instrument for data collection were an 8-point Quantitative Approach to Content Evaluation of Science Textbooks (QACEST) was used to answer research questions 1 and 2 and Flesch Readability Ease Formula used to answer research questions 3. The null hypothesis was tested using chi-square $\left(\mathrm{x}^{2}\right)$ test of goodness of fit at 0.05 alpha level. QACEST was validated using science textbooks and therefore valid. So also the Flesch readability formula and reliability was Kendal Tau coefficient of concordance on data collected from mathematics teachers in junior secondary. The data was ranked and Kendal Tau of concordance applied to establish the reliability. The findings revealed that the contents of the twelve mathematics textbooks evaluated reflected significantly the contents in the core-curriculum as specified, eight out of twelve mathematics textbooks evaluated had chapter summary while New School Mathematics JSS I-III had low chapter summary and all the twelve evaluated mathematics textbooks are fairly readable except STAN mathematics JSS II that is fairly difficult. The textbooks were fairly readable. Based on the findings, the study recommend that all mathematics textbooks used for teaching and learning need to be periodically revised by measurement and evaluation experts. Authors and publishers should draw their objectives and lesson topics or contents from the mathematics core-curriculum. Keywords: Content Coverage, Chapter Summary, Readability, QACEST, Comprehensibility.
\end{abstract}

DOI: $10.7176 / \mathrm{JEP} / 11-27-06$

Publication date:September $30^{\text {th }} 2020$

\subsection{Introduction}

Education is the best investment and books are the basic tools of education. This is in line with Deshmukh's opinion that textbooks are perhaps the most vital learning material available and used in most schools (Abonyi, 2018). Textbooks present a treasure of knowledge to students and also boost students' interest in the subjects. However, Emerole (2008) pointed out that a number of science textbooks are not adequate and are unsatisfactory. If this, instructional material contains any defective knowledge or information, the consequences will be serious on the students and the society in general (Emerole, 2008).

According to Anugwo (2008), a textbook is a printed instructional material used in the teaching and learning process. It normally treats a particular subject and is mostly used in the school for the formal study of a subject. She reiterates that textbooks make contents more meaningful and understandable. Textbook play important role in the teaching and learning of mathematics. They are the most frequently used instructional material for students and teachers at all level. This is because of their availability and ease of use. Mathematics textbooks help students to repeat lesson at home or study before the lesson. These text materials therefore should be written with the vocabulary appropriate for the age and level of students using them. Textbooks must be understandable to students, appropriate for self-study and include accurate information (Abonyi, 2018). Mathematics as a subject contains much abstract knowledge.

Mathematics involves symbols, it is a science of structure, order and relation that has evolved from elemental practices of counting, measuring and describing the shape of objects. People believe that mathematics is difficult and capable of making one mad (Nworgu, 1990). A lot of students all over the world have mathematics phobia and generally see mathematics as a difficult subject. To achieve basic understanding of the nature of mathematics, students have to perceive mathematics as part of scientific endeavour, comprehend and become familiar with the key mathematics ideas and skills. These peculiar problems associated with the learning of mathematics are the bane in maximizing the objectives of imbibing mathematical thinking amongst the students and to curb some of these problems, mathematics textbooks should not be written anyhow (Anugwo, 2008).

Concepts in science do change from time to time rendering an older edition of a book obsolete (Omebe, 2014). Therefore mathematics textbooks have to be continuously evaluated in order to examine the appropriateness and update of the contents of the texts in use so as to give the right type of education as well as meeting up with the dynamic changes in the field of science and technology.

For any programme or curriculum to be effective, it should be thoroughly evaluated in order to assess, 
measure the overall success and identify areas of weakness and make recommendation for change where possible and necessary. The importance of textbook evaluation cannot be overemphasized especially in the areas of content, chapter summary and readability (Omebe, 2014). Textbooks especially mathematics texts, not only govern what is to be taught, but also provide a procedure for teaching the topic. Many of the curriculums in today's schools are to be found in the text books. Therefore, no meaningful teaching and learning can be easily achieved in the absence of a good textbook. According to Omebe, (2014), a good teaching materials include a review of the main theme of the completed chapter. The review is usually in the form of a summary of the main points of a particular chapter and may include chapter review or summary. Thus, the end of chapter review or summary is also an aspect of the content evaluation of textbooks, which should not be ignored, hence, the need to evaluate to determine summaries of basic mathematics textbooks.

It is sometimes desirable in education to measure the difficulty level of a particular text in relation to the class for which it is assigned. One of such measures can be topical coverage is content, chapter summary and readability.

These indices have not been established for mathematics textbooks in use in many countries of the world, also in Nigeria. It therefore becomes critical and very imperatives that the ministries in charge of Education in the various countries of the world be adequately guided in their recommendation of such vital curriculum materials for use in their schools. In addition to justifying the usage of the textbooks, it is necessary to guide the authors on areas of emphasis during farther revisions of the textbooks. The researchers in response to these critical needs therefore, focused on providing a thorough evaluation and unbiased indices of major mathematics textbooks in use in Ebonyi State Junior Secondary Schools of Nigeria.

\subsection{Objectives of the Study}

The objectives of this study are to evaluate mathematics textbooks in Ebonyi State Junior secondary schools. Specifically, this study seeks to:

1. Determine the content coverage of the mathematics textbooks with regard to junior secondary school curriculum.

2. Determine the appropriateness of each of the chapter summary according to class level.

3. Assess the readability index of the mathematics textbooks in use in Ebonyi State Junior Secondary Schools of Nigeria.

\subsection{Scope of the Study}

The research study was carried out in Ebonyi State. The study is delimited to four major mathematics texts approved and in use in the junior secondary schools in Ebonyi State, Nigeria. The mathematics textbooks are:

- $\quad$ MAN mathematics texts for junior secondary schools Book $1-3$ by MAN.

- New General Mathematics textbook for junior secondary school Book 1-3 by M.F. Macrae, Z. I. Chima, J. B. Channon.

- $\quad$ STAN mathematics for junior secondary school Book 1-3 by Godswill Obioma, Donatus-Igbokwe, Ekwo M., Michael Foluso Alonge, Sani Nahuche, Yatunde A. Selau (Miss), Nandin Ladan (Mrs), Mark Ofem Obono, Chima Ogbonna Ubani, Bashir Wada K/Sauri.

- New School Mathematics for junior secondary school Book 1-3 by E.B.U. Ema, Idunisu, Umearu, Jahun, Hector Chee, K.M. Sin, Maria David-Osuagwu. This gives a total of twelve textbooks.

\subsection{Research Questions}

The following research questions guided the study

1. How does the contents of mathematics textbooks in use in Ebonyi State Junior Secondary School correspond with the contents specified in the core-curriculum

2. How adequate are the chapter summaries of the approved mathematics textbooks used in Ebonyi State Junior Secondary Schools?

3. What is the readability index of mathematics textbooks in use in Ebonyi State junior secondary schools?

\subsection{Hypothesis}

The following null hypothesis was tested at an alpha level of 0.05

Ho1: The contents of the mathematics textbooks in Ebonyi State junior secondary schools do not significantly deviate from the specifications of the core curriculum.

\subsection{Research Method}

The study was carried out using evaluation design. Evaluation design. It seeks to ascertain or judge the value of a program or resource by careful appraisal based on pre-stipulated standard. This study involves gathering of information and weighing it with some set of criteria to make judgment regarding the strength and weakness of the recommended mathematics textbooks (Abonyi, 2011). 
Out of the seventeen (17) mathematics texts in use in the three arms of the Junior Secondary schools (bringing it to a total of 51 textbooks for JSS I - III). Simple random sampling technique was used to draw 4 mathematics texts for the three arms i.e. 12 textbooks from the two hundred and twenty one (221) junior secondary schools, seven (7) junior secondary schools were drawn from each of the three (3) education zone through a nonproportionate stratified random sampling technique. In all twenty one (21) junior secondary schools were used in the study.

The mathematics textbooks are:

- $\quad$ MAN mathematics texts for junior secondary schools Book $1-3$.

- $\quad$ New General Mathematics textbook for junior secondary school Book 1-3.

- $\quad$ STAN mathematics for junior secondary school Book 1-3.

- $\quad$ New School Mathematics for junior secondary school Book 1-3.

\subsection{Instrument for Data Collection}

The first instrument is the 8-point quantitative approach for evaluation of science textbooks (QACEST). The model was developed by Emerole (2008). The model evaluated mathematics textbooks based on topical coverage, chapter summary and readability index.

- $\quad$ Topical Coverage Index (TCI)

- $\quad$ Chapter Summary Index (CSI) and

- $\quad$ Readability Index (RI)

The other instrument was flesch readability formula that associates readability solely with features of words and sentences (Marvel, 2007).

\subsection{Validation of the Instrument}

The 8-point quantitative model for science textbook QACEST developed by Emerole (2008) was validated using science textbooks and therefore valid so also the flesch readability formula.

\subsection{Reliability of the Instrument}

The reliability of the 8-point quantitative model for content of mathematics textbooks was done using Kendel Tau coefficient of concordance represented by letter ' $w$ '. 3 mathematics teachers were used for the exercise. The reliability coefficient of $0.79,0.81,0.83$ and 0.93 were obtained for MAN, STAN, New School Mathematics and New General Mathematics respectively.

\subsection{Method of Data Collection}

Data was collected using the 8-point quantitative approach for content evaluation of science textbooks by Emerole (2008) using mathematics textbooks. The junior secondary school mathematics teachers were trained on how to get the indices of topical coverage and chapter summaries while the Flesch Readability Ease (RE) formula was used to get the readability of the sampled textbooks. Two or three passages of above 250 words were sampled from each chapter of the textbook. The average syllables per 100 words and words per sentence were determined by counting and evaluating. All the passages with equations and/or that make much reference to diagram were avoided because they would not encourage smooth reading.

\subsection{Method of Data Analysis}

The 8-point quantitative approach for content evaluation of science textbook by Emerole (2008) was used to answer research questions 1 and 2 and research questions 3 was answered with the flesch readability formula while the hypothesis was tested at 0.05 alpha level of significant using the chi-square of goodness of fit.

\subsection{Result}

3.1 Research questions 1: How does the contents of mathematics textbooks in use in Ebonyi State Junior secondary school correspond with the content specified in the core-curriculum? 
Table 1: Indices of Topical Coverage (ITC) of the Mathematics Textbooks in Use in Junior Secondary School in Ebonyi State.

\begin{tabular}{llllll}
\hline Textbooks & Tt & Ts & St & Ss & Index \\
\hline STAN mathematics for JSS 1 & 11 & 21 & 26 & 41 & 0.58 \\
STAN Mathematics for JSS II & 10 & 14 & 20 & 38 & 0.62 \\
STAN Mathematics for JSS III & 10 & 16 & 25 & 46 & 0.59 \\
New General Mathematics for JSS 1 & 18 & 21 & 33 & 41 & 0.83 \\
New General Mathematics for JSS II & 10 & 14 & 23 & 38 & 0.66 \\
New General Mathematics for JSS III & 15 & 18 & 36 & 46 & 0.81 \\
MAN Mathematics for JSS I & 15 & 21 & 50 & 41 & 0.97 \\
MAN Mathematics for JSS II & 13 & 14 & 21 & 38 & 0.74 \\
MAN Mathematics for JSS III & 18 & 16 & 33 & 46 & 0.89 \\
New School Mathematics for JSS 1 & 8 & 21 & 18 & 41 & 0.41 \\
New School Mathematics for JSS II & 6 & 14 & 17 & 38 & 0.44 \\
New School Mathematics for JSS III & 8 & 16 & 20 & 46 & 0.47
\end{tabular}

Acceptance range- 0.75 to 1.0

The table above revealed the index of the twelve Mathematics textbooks evaluated, indices for STAN Mathematics JSS I-III are $0.58,0.62$ and 0.59 respectively. For New General mathematics, the indices for JSSIIII are 0.83, 0.66 and 0.81. MAN Mathematics JSS I-III had 0.97, 0.74 and 0.89. While the ITC for New School Mathematics JSSI-III are $0.41,0.44$ and 0.47 respectively.

3.2 Research question 2: How adequate are the chapter summaries of the approved mathematics textbooks used in junior secondary school in Ebonyi State?

Table 2: Chapter Summary Index (CSI)

\begin{tabular}{llllll}
\hline Textbooks & Js & Jc & Ns & Nc & Index \\
\hline STAN Mathematics for JSS 1 & 58 & 124 & 8 & 10 & 0.86 \\
STAN Mathematics for JSS II & 84 & 151 & 5 & 4 & 0.68 \\
STAN Mathematics for JSS III & 69 & 136 & 8 & 7 & 0.69 \\
New General Mathematics for JSS 1 & 88 & 83 & 7 & 6 & 0.96 \\
New General Mathematics for JSS II & 105 & 107 & 7 & 6 & 0.92 \\
New General Mathematics for JSS III & 66 & 79 & 8 & 7 & 0.86 \\
MAN Mathematics for JSS 1 & 88 & 78 & 7 & 1 & 0.64 \\
MAN Mathematics for JSS II & 98 & 165 & 13 & 12 & 0.76 \\
MAN Mathematics for JSS III & 133 & 177 & None & None & 0.38 \\
New School Mathematics for JSS 1 & None & None & None & None & None \\
New School Mathematics for JSS II & None & None & None & None & None \\
New School Mathematics for JSS III & None & None & None & None & None
\end{tabular}

Acceptance range $=0.60$ to 1.00

From table 2 above, the results of CSI were presented. For STAN Mathematics JSS I-III, the CSI are 0.86, 0.68 and 0.69. For New General Mathematics JSS I-III, the CSI are 0.96, 0.92 and 0.86. For MAN Mathematics JSS I-III, the CSI are 0.64, 0.76 and 0.38. New School Mathematics JSS I-III had no CSI. The result shows that New General Mathematics JSS I-III had higher CSI among the evaluated textbooks while New School Mathematics had none. 
3.3 Research question 3: What is the readability index of mathematics textbooks in Ebonyi state?

Table 3: Readability and Comprehensibility Index (RCI)

\begin{tabular}{lll}
\hline Textbooks & Score & Readability \\
\hline STAN Mathematics for JSS I & 61 & Standard \\
STAN Mathematics for JSS II & 51 & Fairly difficult \\
STAN Mathematics for JSS III & 79 & Fairly easy \\
New General Mathematics for JSS I & 73 & Fairly easy \\
New General Mathematics for JSS II & 72 & Fairly easy \\
New General Mathematics for JSS III & 74 & Fairly easy \\
MAN Mathematics for JSS I & 73 & Fairly easy \\
MAN Mathematics for JSS II & 72 & Fairly easy \\
MAN Mathematics for JSS III & 61 & Standard \\
New School Mathematics for JSS I & 64 & Standard \\
New School Mathematics for JSS II & 87 & Easy \\
New School Mathematics for JSS III & 79 & Fairly easy
\end{tabular}

Acceptance range $=$ between 50 to 90

The data on table 3 above shows the RCI for the twelve Mathematics textbooks evaluated. RCI for STAN Mathematics textbook JSSI was 61, JSSII was 51, JSSIII was 79. For New General Mathematics, JSSI was 73, JSSII was 72 and JSSIII was 74. For MAN Mathematics, JSSI was 73, JSSII was 72 and JSSIII was 61. New School Mathematics JSSI was 64, JSSII was 87 and JSSIII was 79. New School Mathematics JSSII with RCI of 87 is the most readable (i.e. easy).

\subsection{Hypothesis}

Ho1: The content of the mathematics textbooks in Ebonyi State Junior Secondary School do not significantly deviate from the specification of the core-curriculum.

Table 4: Chi-square (x2) table on significance of deviation of content of mathematics textbooks JSS I - III from core-curriculum

\begin{tabular}{|c|c|c|c|c|c|c|}
\hline Textbooks & Major topics & Minor topics & $\mathrm{x}^{2} \mathrm{cal}$ & Alpha & $\mathbf{x}^{2}$ crit & Decision \\
\hline STAN Mathematics Textbook JSS I & $11(21)$ & $26(41)$ & & & & \\
\hline STAN Mathematics Textbook JSS II & $10(14)$ & $20(38)$ & 33.11 & 0.05 & 12.592 & Reject \\
\hline STAN Mathematics Textbook JSS III & $16(10)$ & $25(46)$ & & & & \\
\hline New General Mathematics JSS I & $18(21)$ & $33(41)$ & & & & \\
\hline New General Mathematics JSS II & $10(14)$ & $23(38)$ & 11.72 & 0.05 & 12.592 & Accept \\
\hline New General Mathematics JSS III & $15(18)$ & $36(46)$ & & & & \\
\hline MAN Mathematics JSS I & $15(21)$ & $50(41)$ & & & & \\
\hline MAN Mathematics JSS II & $13(14)$ & $21(38)$ & 12.13 & 0.05 & 12.592 & Accept \\
\hline MAN Mathematics JSS III & 19(16) & $43(46)$ & & & & \\
\hline New School Mathematics JSS I & $8(21)$ & $18(41)$ & & & & \\
\hline New School Mathematics JSS II & $6(14)$ & $17(38)$ & 55.83 & 0.05 & 12.592 & Reject \\
\hline New School Mathematics JSS III & $8(16)$ & $20(46)$ & & & & \\
\hline
\end{tabular}

The contents of the mathematics textbooks were matched with the content specified in the core-curriculum. The frequencies were subjected to a chi-square test of goodness fit and presented on table 4 above. For STAN textbooks, the chi-square $\left(\mathrm{x}^{2}\right)$ calculated is 33.11 while New General Mathematics it is 11.72 . It is 12.13 for MAN and 55.83 for New School Mathematics. The chi-square critical ( $\mathrm{x}^{2}$ crit) at alpha level of 0.05 is 12.592 . The researchers therefore reject the null hypothesis for STAN and New School Mathematics and conclude that the content of the STAN and New school mathematics textbooks significantly deviate from the specification of the core-curriculum. The null hypothesis is accepted for New General Mathematics and MAN textbooks because they do not deviate significantly from the core-curriculum. 


\subsection{Summary of the Results}

From the evaluation, it was revealed generally that:

Four out of the twelve evaluated mathematics textbooks covered the content as stipulated by the curriculum. These are MAN mathematics for JSS I (0.97) followed by MAN mathematics JSS III (0.89), New General mathematics for JSS I (0.83) and New General mathematics JSS III (0.081). The least among the textbooks evaluated is New School mathematics JSS I which has ITC of 0.41.

In answer to research question 2, CSI for all the twelve mathematics textbooks evaluated lies within the acceptance range of 0 to 1.00. New General Mathematics JSS I had the highest indices of 0.96. New School Mathematics Textbooks JSS I - III had no chapter summary.

Finally, Research Question 3 is on the readability of the approved Junior Mathematics Textbooks evaluated. According to Flesch Read Ease Score interpretation, New School Mathematics is easy with readability score of 87 while STAN Mathematics JSS II is fairly difficult with readability score of 51.

\subsection{Discussion \\ 4.1 Content Coverage}

Content coverage of textbooks is an important issue to look into when evaluating a textbook. From the results of this study, it was found that the content coverage of some mathematics textbooks is high above the acceptance range while some fall within the acceptance range of 0 to 1.00. The result obtained from the collected data show that the Indices for the tropical coverage (ITC) of STAN Mathematics for JSS I, JSS II and JSS III are $0.58,0.62$ and 0.59; ITC for New General Mathematics JSS I - III are 0.83, 0.66 and 0.81. MAN Mathematics textbooks for JSS I -III are 0.97, 0.74 and 0.89 and ITC for New School Mathematics JSS I - III are 0.41. 0.44 and 0.47.

Teachers depend on textbooks when teaching and students depend on textbooks when learning and for that textbook content coverage must correspond with the curriculum. The results of the findings agree with the findings of other researchers. Tok (2010) reported in his work that the content coverage of mathematics textbook evaluated is fairly adequate.

The findings in this work show that the mathematics textbooks in use in Ebonyi State Junior Secondary Schools closely reflect the specification of the curriculum.

\subsection{Adequacy of the Chapter Summary}

For the adequacy of the chapter summary of mathematics textbooks, the analysis of the data collected for the study and results obtained indicated that among the 12 evaluated mathematics textbooks in-use in Ebonyi State Junior Secondary Schools New School Mathematics. JSS I. JSS II and JSS III had no chapter summary. The chapter summary index (CSI) for STAN Mathematics JSSI, JSS II and JSS III are 0.86, 0.68 and 0.69 for New General Mathematics JSS I, JSS II and JSS III are $0.96,0.94$ and 0.86 while CSI for MAN Mathematics JSS I, JSS II and JSS III are 0.64, 0.76 and 0.38 . The result shows that STAN Mathematics textbooks, New General Mathematics textbooks and MAN Mathematics textbooks had high chapter summary except MAN Mathematics textbook JSS III with low chapter summary. The findings are in line with Nwafor (2012), who evaluated content and adequacy of Primary Science Textbooks in public primary schools in Ebonyi State. The study revealed that the Primary Science textbooks were adequate in terms of contents learning activities and chapter summary.

\subsection{Readability}

On the readability of the mathematics textbooks, the scores obtained from most of the textbooks are fairly easy. Their scores lies between 70 - 80. New School Mathematics JSS II score highest while STAN mathematics textbook scored lowest making the textbooks to be fairly difficult. Readability of mathematics text is difficult to ascertain because of the complex nature of mathematics text.

The findings are in line with Omebe (2014) whose work on readability of approved Basic Science Textbooks in-use in Ebonyi State revealed that there is little variation in the readability of Basic (Science textbooks evaluated. From the result of this study mathematics textbook in-use in Junior Secondary Schools are readable.

\subsection{Summary}

The study centered on evaluating mathematics textbooks in-use in Ebonyi State Junior Secondary Schools based on their content coverage, chapter summary and readability on the approved mathematics textbooks. The study evaluated 12 mathematics textbooks out of the 51 approved mathematics textbooks. The textbooks are STAN mathematics JSS I-III, New general mathematics JSS I-III. MAN mathematics JSS I-III, New school mathematics JSS I-III.

\subsubsection{The results of the work revealed that:}

1. The contents of the twelve mathematics textbooks evaluated reflected significantly the contents in the core-curriculum as specified.

2. Eight out of twelve mathematics textbooks evaluated had chapter summary while new school 
mathematics JSS I - III had no chapter summary.

3. All the twelve evaluated mathematics textbooks are fairly readable except STAN mathematics JSSI 1 that is fairly difficult.

\subsection{Conclusions}

The following conclusions were made based on the finding; from the study.

1. The twelve evaluated mathematics textbooks had contents that specifically reflect in the core-curriculum. Therefore, the mathematics textbooks used Ebonyi State Junior Secondary Schools are good even though none of the textbooks is perfect in content coverage.

2. The chapter summary of all the mathematics textbooks in-use in Ebonyi State Junior Secondary Schools were adequate except New School Mathematics textbooks.

3. Based on the readability scores as interpreted by Cheryl (2003), only one mathematics textbook (New school mathematics) is easy while others are fairly easy, fairly difficult and standard in their readability. STAN mathematics JSS I, MAN mathematics JSS III and New School mathematics JSS I are standard with readability scores of $61,61.64$. STAN mathematics JSS II is fairly difficult with readability score of 51, while STAN mathematics JSS III, NGM JSS I - III, MAN JSS I -II. NSM JSS III are fairly easy.

\subsection{Recommendation}

Authors should endeavour to have mathematics core-curriculum whenever they are writing textbooks. This will make them to be aware of the topics, performance objectives and contents in each textbooks. Textbooks should equally be revised periodically by experts in this field to avoid recommending the wrong books to the students.

\subsection{References}

Abonyi, O.S. (2011). Instrumentation in behavioural research (A practical approach). Enugu. TIMEX.

Abonyi O.S., Ogbu, R., Nnachi, N.O., and Ugama, J.O. (2018). Content coverage and readability of biology textbooks in use in Nigerian secondary schools. Middle-East Journal of Scientific Research, 26(4), 432-437.

Anugwo, M.N. (2008). Evaluation of selected mathematics textbooks in use in senior secondary school in Ebonyi State. Unpublished Ph.D Dissertation submitted to the Department of Education Psychology, Guidance and Counselling University of Port Harcourt.

Cheryl, S. (2003). Bitcoin tools readability indices, removed 02-07-2007 from http://www.swinededu/bitcoin/fog.htm. Accessed on 8th April, 2015.

Emerole, H.U. (2008). A quantitative evaluation approach for science textbooks: An 8-point model. Department of Mathematics and Science Education. Unpublished Thesis, University of Botswana.

Nwafor, C.E. (2012). Evaluation of some approved primary science textbooks in use in public primary schools in Ebonyi State of Nigeria. The Intuition, 2(1), 4-8.

Nworgu, B. G. (1990). A quantitative approach to content evaluation of science textbooks (QACEST). In D. A. Onyejemezi (ed). Educational Technology in Nigeria Education. Onitsha: Summer Educational Publisher, 209-218.

Omebe, C. A. and Nnachi, N.O. (2014). Evaluation of content and chapter summaries of approved basic science textbooks in Ebonyi State Junior Secondary Schools in Nigeria. Journal of Education and Practice, 3(35), $36-40$.

Tok, H. (2010). TEFL textbook evaluation: From teachers' perspective. Educational Research and Review, 5(9), 508-517. 